\title{
Review on Safe Electric Mobility for Women Rider
}

\author{
Kshitij Shinghal ${ }^{1}$, \\ ${ }^{1}$ Head of the Department, \\ Electronics and Communication Engineering Department, \\ Moradabad Institute of Technology, Moradabad
}

\author{
Amit Saxena ${ }^{2}$ \\ ${ }^{2}$ Assistant Professor, \\ Electronics and Communication Engineering Department, \\ Moradabad Institute of Technology, Moradabad
}

\author{
Mini Katariya ${ }^{3}$, Hiwani Singh ${ }^{3}$, Shahbaz Khan $^{3}$ \\ ${ }^{3}$ Student, \\ Bachelor of Technology (ECE), \\ Moradabad Institute of Technology, Moradabad
}

\begin{abstract}
Increase in number of crimes against women as been a major concern from the past years in the country. The rise in use of vehicles has caused a threat of human life as well as environment due to pollution caused by the vehicles. And the increase in number of death rates due to accidents has been another threat to life. Immense technological advancements have been made in the field of safe electric mobility by engineers to reduce the above stated concerns. The current paper looks at the solutions that are possible to reduce the crimes against women by empowering them to fight against the crimes, along with reducing the number of accidents and pollution. This paper provides information on an existing hybrid bike that has performance and safety, and is designed especially for the safety of women.
\end{abstract}

Keywords - Electric vehicle, women safety, crash alert, dual fuel, safe electric mobility, performance features, safety features, hybrid bike.

\section{INTRODUCTION}

The safety of women has been a primary concern after the rise in the number of crimes in the country. Secondly, the rise in $\mathrm{CO}_{2}$ due to vehicles caused air pollution, which is harmful to human as well as environment. Lastly, the number of crashed and collision has increased with an alarming rate. The engineers have designed a safe electric mobility for women rider, which is a hybrid bike, having various performance and safety features. In this paper, the information about this hybrid bike is discussed. This paper is organized in different sections.

In section 1, a brief introduction is given about this safe electric mobility. The literature survey about different research papers is given in section 2. The outcome of the survey is explained in section 3. The paper is concluded in section 4. In the last section, the future aspect of this vehicle is given.

\section{LITERATURE SURVEY}

\subsection{A Survey on Electric and Hybrid Electric Vehicle Technology [1]}

According to this paper, climate change and the rapid vanishing of global crude-oil stock are the concerns of the world. The degradation in air quality due to exhaust gas and loud noise from cars in cities has resulted in a struggle to replace these vehicles from the electric vehicles. Even though progress is carried in the field of electric vehicle technology, few barriers are still to be overcome. Firstly, the price of these electric vehicles has to lowered mainly due to battery cost, the technologies need to be advanced, secondly, the range of driving has to be extended in electric vehicles, with reasonable battery prices; lastly, the infrastructure in electric vehicles has to be carried out. Since this problem is very complex therefore, it deserves cooperation of governments, technical engineers, researchers, etc, to establish standards, for instance, in the infrastructure of battery and power grid energy taxes.

\subsection{Recent Development on Electric Vehicles [2]}

In this paper, the discussion is about electrical vehicles and hybrid electric vehicle. The electric vehicle is based on electric propulsion system. In these vehicles, there is no use of an internal combustion engine. As energy source, the power is solely based on electric power. One main advantage in power conversion is the high efficiency through its proposition system of electric motor. The hybrid electric vehicle is an alternative of electric vehicle. In these vehicles the main source is DC battery voltage. High power is required for the battery system for both slow charging and fast charging.

\subsection{Overview of Electric Vehicle Concept and Power Management Strategies [3]}

The discussion in this paper is about the various technologies that are used in hybrid electric vehicle, plugin hybrid electric vehicle, battery electric vehicle, fuel cell electric vehicle and solar electric vehicle. Being an electric vehicle, the main element is batteries. Preferably, the use of Lithium ion batteries are done, due to these batteries being environment friendly, high energy density, long life span and high power density then conventional batteries. The paper tells that they will focus on enhancing the power management supervisory level. They aim to optimize a multi power source management in battery electric vehicle and hybrid electric vehicle.

\subsection{Overview of Electric and Hybrid Vehicles [4]}

This paper gives the information on battery electric vehicle and hybrid electric vehicle. The various configuration are 
given in the hybrid electric vehicle, which are series hybrid electric vehicle, parallel hybrid electric vehicle, seriesparallel hybrid electric vehicle, complex hybrids, fuel cell hybrid electric vehicle and plug-in hybrid electric vehicle. The future is said to be the electric vehicle, as the petroleum will run out within 50 to 60 years, as defined in the paper. Therefore, it is predicted that everyone will soon start using electric vehicle.

\section{OUTCOME OF THE SURVEY}

After the study about various technologies, from different research papers, used in the vehicles, it was found that there are quite a lot of limitations in the existing technologies. There are electric vehicles, yet none were dual fuel. These vehicles did not have safety or performance features for the rider. The safe electric mobility designed by the authors has these features. There were various considerations and elements considered by the authors, when this vehicle was being designed. Safety of women was a primary concern for the authors, since this electric vehicle is especially designed for the safety of women.

\section{CONCLUSION}

Surveying the above papers, it was noted that in the coming future, petroleum will run out, therefore most people will shift to electric vehicles. The primary concern being the safety of the women, therefore, the proposed model is mainly designed for the safety of women. This model has crash and collision alert as well, to avoid any hazardous situation. The electric vehicles that were reviewed were mainly focussed on reducing the price and the batteries that were used, could be charged faster. The authors mainly focused on developing a safe electric mobility, especially for a women rider.

\section{FUTURE ASPECT}

The authors have proposed this model for the safety of the women, which is the main objective of designing this vehicle. At present, the vehicles run on either petrol or diesel but, this scooty can run on dual fuel. By 2030, most people must start using electric vehicles as per National Electric Mobility Mission Plan (NEMMP)-2020, that was launched by Govt. of India in 2013; therefore using a hybrid electric vehicle could help in riding electric vehicle. [5] Therefore, this vehicle can be used by most people. Electric Vehicle is the rising star of the industry, but it needs advancement in various dimensions, like controller use, better circuits for smooth driving experience, new battery material for long range with short charging time, regenerative breaking can be introduced to compensate the friction losses and utilizing the losses into energy.

\section{ACKNOWLEDGEMENT}

The authors would like to express deepest sense of gratitude towards Dr. Rohit Garg (Director MIT Moradabad), parents and friends for their patience, inspiration, guidance, constant encouragement, moral support, keen interest, and valuable suggestions during preparation of this review paper.

\section{REFERENCE}

[1]. Samuel E. de Lucena (September 6th 2011). A Survey on Electric and Hybrid Electric Vehicle Technology, Electric Vehicles - The Benefits and Barriers, Seref Soylu, IntechOpen, DOI: $10.5772 / 18046$.

[2]. Cheng, K.W.E.. (2009). Recent development on electric vehicles. 2009 3rd International Conference on Power Electronics Systems and Applications, PESA 2009. 1 - 5.

[3]. Flah, Aymen \& Lassaad, Sbita \& Mahmoudi, Chokri. (2014). Overview of Electric Vehicle Concept and Power Management Strategies. 2014 International Conference on Electrical Sciences and Technologies in Maghreb, CISTEM 2014. 10.1109/CISTEM.2014.7077026.

[4]. Vidyanandan, K.V.. (2018). Overview of Electric and Hybrid Vehicles. Energy Scan (A House Journal of Corporate Planning, NTPC Ltd., India). III. 7-14.

[5]. https://pib.gov.in/newsite/PrintRelease.aspx?relid=1 